\title{
Video Conferencing in Higher Education: a Case Study of Indonesian Lecturers
}

\author{
Harmilawati ${ }^{1}$, Sabaruddin $^{2}$, Sitti Aminah ${ }^{3}$, Hamka $^{4}$ \\ \{iladilla1986@gmail.com ${ }^{1}$ \} \\ Faculty of Education and Teacher Training, Islamic Institute of Muhammadiyah Sinjai, Indonesia 1,2,3 \\ Faculty of Economicand Islamic Law, Islamic Institute of Muhammadiyah Sinjai, Indonesia ${ }^{4}$
}

\begin{abstract}
The global pandemic of COVID-9 impacts all sectors of human life, including education. The teaching processes previously done face to face in the classroom have to be conducted online. It increases the utilisation of video conferencing app in teaching activities replacing face to face meeting in higher education. This study aims to investigate lecturers' perspective regarding the use of video conferencing in Indonesian higher education. This study was conducted using a qualitative methodology within case study design. Three lecturers from different universities in Indonesia participated in this research study. To collect data, online semi structured interviews were done via WhatsApp. The collected data from the interviews were then evaluated using thematic analysis. The findings of this research show that the lecturers have positive attitudes towards the use of video conferencing in distance learning which they value due to the perceived benefits in terms of teaching creativity and enhancement of their technological knowledge. Although the lecturers encountered several challenges in using video conferencing in teaching, such as limited interaction and internet accessibility, they have their own strategies to minimise those issues.Having aimed to provide lecturers' perception into the use of video conferencing in higher education setting, the findings of this study offer several recommendation for educators, policy makers and future researchers.
\end{abstract}

Keywords: Conferencing, distance learning, teaching, higher education

\section{Introduction}

The enhancement of Internet and Communication Technology (ICT) in recent decades impacts the system of education. The teaching and learning activities now can be conducted virtually using some online learning platforms. Video conferencing is one of the online platforms used by educators. According to [3], video conferencing is a synchronous model of interaction between two or more people for interactive video, voice and data transfer. It can facilitate sharing of files, applications, and electronic workspaces [11]. This online platform has been gaining acceptance around the world, especially in the COVID-19 pandemic. Learning process, which is initially run in the classroom, due to the pandemic, has to be done online. Thus, educators are encouraged to use online platforms in conducting a teaching process.

Currently, video conferencing is one of the most prevalent online platforms used by the teachers to replace the face-to-face meeting [13]. It is because video conferencing can create an interesting and convenient distance learning and it makes it possible to deliver learning material in an interactive way through creative presentation [1]. Additionally, video conferencing apps, such as Zoom Meeting, Google Meeting and Webex allow teachers to connect with their 
students without meeting physically [7]. Furthermore, according to [12], video conferencing can foster the learning independence of students. Using video conferencing also gives opportunities for teachers and students to develop their technological competencies [5]. Therefore, due to its advantages, this online platform becomes popular among educators.

However, along with the use of video conferencing in teaching and learning process, some issues emerge. Firstly, the quality of video conferencing system and bandwidth affect the level of interaction between teachers and students [7]. Secondly, the dominant role of teachers in the teaching process when using video conferencing contributes to the low involvement of students [4]. Thirdly, students' learning styles and unfamiliarity with this new technology affect their learning motivation [3]. In addition, unstable internet connection is also a big challenge in applying video conferencing [8]. Thus, in order to apply video conferencing in teaching appropriately, those issues need to be considered.

Many research studies exploring the utilization of video conferencing in education context were conducted. For instance, [2] have done a research to find out challenges of video conferencing use in educational context in Africa. Also, [3] did a research study to investigate the students' voice regarding the use of video conferencing in Turkey's classroom. Results of [3] shows that most of students have a negative attitude towards the use of video conferencing. In contrast, research organized by [4], [7] and [14] found that students tend to have a positive perception regarding the use of video conferencing in distance learning. Nevertheless, studies in the field of video conferencing were much more focusing on learners' perception, while studies investigating educators' perception remain limited. Concerning to the problem, this research study, therefore, aims to investigate the lectures' perspective of video conferencing use in Indonesian higher education context.

This study proposed a research question: how lecturers in Indonesia higher education perceive the use of video conferencing in teaching process? This question is designed to explore the lectures' attitudes towards the use ofvideo conferencing, specially, their voice in terms of benefits of this online platform. It also aims to explore the challenges faced by the lecturers when utilizing video conferencing in teaching and how they adapt with those issues. Addressing this area, this research seeks to fill the gaps within literature. The results of this study could inform other lecturers in Indonesia on how to apply video conferencing in teaching practices, encourage the policy makers and researchers to consider this teaching technique.

\section{Method}

A qualitative methodology within case study design is used in this research. This methodology is chosen because it emphasises the understanding of social reality by examining respondents' interpretations. It is aligned with the study's research question, which is formulated for an in-depth examination of Indonesian lecturers' perceptions regarding the of video conferencing in higher education.

\subsection{Participant}

This is a small-scale research study, so only three lecturers from different universities in Indonesia who have an experience in using video conferencing for educational purpose participated in this study. Participant A is a 30-years-old male with 8 months' experience in using video conferencing in teaching. Participant B is a 27 years-old male who has 7 months 
teaching experience utilising video conferencing. Additionally, participant $\mathrm{C}$ is a 28 years-old male with more than a year experience in using video conferencing in teaching practices. The participants were selected using purposive sampling.

\subsection{Data collection}

In terms of data collection, this study utilised an online semi-structured interview strategy. The participants were interviewed via WhatsApp by using an interview guide. This interview guide allows the researchers to openly prompt new question in order to find more information from the respondents and the respondents freely to answer based on their teaching context. Subsequently, the interviews were recorded to ensure all data from the interview wasincluded in the analysis.

\subsection{Data analysis}

To analyse the data, a thematic analysis technique was applied in this study. Before analysing the data, the interview recordings were transcribed. The transcripts were then analysed through a series of coding and identification of several important themes that emerge from the interview transcripts.

\section{Result and Discussion}

\subsection{Results}

From the analysis of the interview transcripts, three main themes emerged: lecturers' attitudes of video conferencing, benefits, challenges of video conferencing and adaptive action of the lecturers towards the potential obstacles.

First of all, all lecturers have a positive attitude regarding the use of video conferencing in higher education. It can be seen from their responses. For example, Participant B argued that 'I enjoy using video conferencing because it gives me an opportunity to use new learning strategies and develop my teaching skill'. Participant $C$ also mentioned that ' $I$ will use this online platform even the post-pandemic since I find this is useful, especially in this industrial revolution 4.0. Furthermore, all participants hope that the use of video conferencing can be optimise through the application of blended learning system in higher education. As argued by Participant A 'I get used to video conferencing and I expect that Indonesian Higher Education will apply blended learning system by incorporating video conferencing". Participant B also said that 'I predict the video conferencing will be used more in the future through the blended learning system'

Secondly, the respondents stated that video conferencing is beneficial in terms of developing their technological knowledge. For instance, Respondent A explained that 'using video conferencing gives me a new knowledge and experience on how to use technology in teaching. Also, Respondent $\mathrm{C}$ said that 'It gives me a priceless experience in terms of my skill in using technology'. Furthermore, video conferencing develops teaching creativity of the lecturers. As an example, Respondent B explained that 'it enhance my teaching creativity in terms of preparing and creating learning materials'. Also, Respondent $\mathrm{C}$ mentioned that 'using video conferencing challenges me to be creative'. 
Thirdly, besides the benefits, the participant also encountered several challenges when using video conferencing. Participant A noted that 'my interaction with my students is limited and students seem passive when using video conferencing. Participant B also explained that "my students participation is low, the discussion is dominated by same students all the time" and Participant $\mathrm{C}$ said that 'the students looks shy and no response when I ask them to give a question'. Furthermore, internet connection also becomes an issue in the use of video conferencing. All the participant admitted that students' accessibility to the internet connection is a big challenge. For example, Participant A explained, my students frequently lose connection because of their connection'. Additionally, Participant $\mathrm{C}$ experienced that 'not all my students can attend video conferencing due to the internet problem'.

Nevertheless, the participants have their own strategies to adapt with those obstacles. For example, Participant A argued that 'to improve my students' participation, I create interactive and interesting presentation. Also Participant B mentioned that 'I use an online application to randomly chose my students to give opinion or question, so all students can participate'. In terms of internet connection, Participant $\mathrm{C}$ argued that 'I make learning flexible, I do not force all my students to join video conferencing, only who have an internet connection'. In addition, Participant A said that 'I gives longer assignment due date for my students, so they can do the assignment when they connect to the internet".

\subsection{Discussion}

The result of this research study shows that all participants perceived the use of video conferencing positively because they enjoy using it and expected to apply the online platform in the future. This finding is consistent with some previous studies that also found that most of educators have a positive attitude regarding video conferencing use in education $[1,9,11,13]$. According to [1], overall, teachers were happy with the use of video conferencing. [9] also argues that teachers believed that video conferencing is potential for future education. Additionally, [13] found that lecturers in Japan admit that video conferencing is an effective tool to help connect with their students in Australia.

In addition, lecturers in this study mentioned that video conferencing is useful to develop their technological skill. It is in line with the research finding of [12] that using video conferencing impacts the technological skill of teachers as well as students because they learn to use it and at the end of the they, they become familiar with the online application. Video conferencing also encourages their creativity as mentioned by the participants in this study. This support argument of $[8,5]$ who explained that using an online platform, such as video conferencing, educators need to be creative and innovative.

Furthermore, this study also found several challenges in utilising video conferencing; limited interaction and internet connection. Most of research studies [1, 2, 6 12, 13] experienced the issues. For example, [2] mentions that the most obvious challenge of video conferencing is the low participation and limited interaction of learners in discussion. Moreover, [13] argues that the learners look unmotivated to involve in the learning process. Additionally, [6] expressed that, using video conferencing should consider the internet availability since it is the main infrastructure for distance learning. However, in this study recommends several strategies explained by the participant to adapt with the issues which is creating interesting and flexible learning. Interesting learning could enhance students' active participation, while flexible learning could accommodate students with limited access to the internet. 


\section{Conclusion}

This study aimed to investigate lecturers' perception regarding the use of video conferencing in Indonesian higher education setting. This study was conducted within qualitative case study design. The results of this study indicated that the three lecturers have a positive attitudes in terms of video conferencing use in teaching activities. It is because they found it beneficial in terms of development of their technological competence [5] and teaching creativity [1]. Although facing challenges; limited interaction [2] and internet connection [6], they have their own techniques to minimise those issues by implementing interesting and flexible learning.

This study has several implication for educational practice, research and regulation. This results of this study could be a consideration by other lecturers in using video conferencing, fill a gap within the video conferencing literature and encourage the policy makers to regulate the future use of video conferencing in educational sector. Nonetheless, the findings of this smallscale study are not able to be generalised because it only involved limited participants with specific context. Therefore, it is strongly suggested that the future studies are conducted using mixed method (qualitative and quantitative) involving a large number of participant, so the studies could provide fruitful and broad findings.

\section{Acknowledgements}

We would like to acknowledge LP2M (research council) of Islamic Institute of Muhammadiyah Sinjai who supports and grants this study, so this study can be completed.

\section{References}

[1] A. A. M. H. Al-Ahdal and A. A. Al-Hattami, "Assessing teachers' and students' perceptions about teaching and learning using videoconferencing method of instruction," Acad. Res. Inter., vol. 5, no. 1, pp. 111-119,Jan. 2014.[Online].Available: http://www.journals.savap.org.pk

[2] C. Niyizamwiyitira, "Teaching using videoconferencing: Approaches and challenges," Lärar., p. 104-123, 2016. [Online]. Available: http://dx.doi.org/10.15626/lld.201506

[3] D. Candarli and H. G. Yukselb, "Students' perceptions of video-conferencing in the classrooms in highereducation,"Procedia Soc. Behav. Sci., vol. 47, pp. 357 361,2012, doi:10.1016/j.sbspro.2012.06.663

[4] D. Gillies, "Student perspectives on Videoconferencing in teacher education at a distance," Dis. Edu., vol. 29, no. 1, pp. 107-118, May. 2008, doi: 10.1080/01587910802004878

[5] D. G. Krutka and K. T. Carano,"Videoconferencing for global citizenship education: Wise practices for social studies educators," JSSER., vol. 7, no. 2, pp. 109-136, 2016. [Online]. Available: https://files.eric.ed.gov/fulltext/EJ1121636.pdf

[6] D. Martinovic, T. Pugh andJ. Magliaro, "Pedagogy for mobile ICT learning using videoconferencing technology," Journal of Infor. Know, Manag., vol. 5, pp. 376-394, 2010. [Online].Available: http://www.ijikm.org/Volume5/IJIKMv5p375-394Martinovic518.pdf

[7] H. Karal, A. Çebi and Y. E. Turgut, "Perceptions of students who take synchronous courses through video conferencing about distance education," TOJET., vol. 10, no. 4, pp. 276-293, Oct. 2011. [Online]. Available: http://www.tojet.net/articles/v10i4/10428.pdf

[8] L. Coventry, " Video conferencing in Higher Education, January 2015 
[9] M. Martin, "Seeing is believing: The role of videoconferencing in distance learning," British Journal of Edu. Tech., vol. 36, no. 3, pp. 397- 405, 2005. [Online]. Available: https://doi.org/10.1111/j.14678535.2005.00471.x

[10] P. Gladović and N. Deretić, "Video conferencing and its application in education," JTTTP., vol. 5, no. 1, pp. 45-48, 2020, doi: 10.7251/JTTTP2001045G

[11] R. Roberts, "Video conferencing in distance learning: A New Zealand schools' perspective," Journal of Distance Learning., vol. 13, no. 1 , pp. $91-$ 107, 2009. [Online].Available: http://www.jofdl.nz/index.php/JOFDL/article/viewFile/40/38

[12] R. Wang and R. Wiesemes, "Enabling and supporting remote classroom teaching observation: live video conferencing uses in initial teacher education,” Tech. Peda. Edu., vol. 21, no. 3, pp. 351-360, Oct. 2012. [Online]. Available: http://dx.doi.org/10.1080/1475939X.2012.719397

[13] S. Yasumoto, "Teaching and learning in the digital era: a case study of video-conference lectures from Japan to Australia," Sustain. Tech. Edu., pp. 42-50, 2014. [Online]. Available: https://files.eric.ed.gov/fulltext/ED557323.pdf

[14] Y. B. Permatasari, "Male and female students' perceptions toward the implementation of video conference as a distance learning media that enhances teachers' productivities," Journal of App. Ling. Lit., vol.2, no. 2, pp.101-112, Sep.2018. [Online]. Available:https://jurnal.unigal.ac.id/index.php/jall/index 